\title{
A antinomia da proposta de humanização do cuidado em saúde
}

\section{The antimony of the health care humanization proposal}

\author{
Diego de Oliveira Souza ${ }^{a}$ \\ aUniversidade Federal de Alagoas, Campus Arapiraca, \\ Departamento de Enfermagem. Arapiraca, AL, Brasil. \\ E-mail: enf_ufal_diegoळhotmail.com \\ Jane Carla Mauríciob \\ bUniversidade Federal de Sergipe. Residência multiprofissional \\ em saúde do adulto e idoso. Aracaju, SE, Brasil. \\ E-mail: janecenf@gmail.com
}

\section{Resumo}

Este ensaio busca contribuir para a (re)formulação de uma linha teórica de análise da humanização do cuidado em saúde, a partir de uma abordagem marxiana. Para tanto, dialogamos com parte da produção científica brasileira, quando constatamos a predominância de uma tendência que centra a estratégia de humanização sobre uma perspectiva subjetiva-relacional, especialmente explícita na Política Nacional de Humanização da Atenção e Gestão no Sistema Único de Saúde. Embora reconheçamos a importância dessa estratégia, apontamos seus limites, ao problematizar o que seja humanização em Marx e, por consequência, demonstrando a estrutura originária do processo de desumanização. Feito isso, esclarecemos que, considerando quais sejam as bases da desumanização, seu enfrentamento deve ir além da esfera subjetiva-relacional, no sentido de atingir a dimensão coletiva da luta de classes, contra o capital. Trata-se de articular a luta particular contra os efeitos desumanizadores do capital na saúde com a luta mais geral, contra o capital nas suas linhas mais fundamentais.

Palavras-chave: Capitalismo; Cuidados de Saúde; Humanização; Marxismo.

\section{Correspondência}




\section{Introdução}

This essay seeks to contribute to the (re) formulation of a theoretical framework to analyze the humanization of health care, from a Marxian approach. For such, we dialogued with part of the Brazilian scientific production, in which we find the predominance of a trend that focuses on a humanization strategy from a subjective relational perspective, especially clear in the Política Nacional de Humanização da Atenção e Gestão no Sistema Único de Saúde (Brazilian Humanization Policy of Care and Administration in the Unified Health System). Although we acknowledge the importance of this strategy, we point its limits when discussing the concept of humanization from Marx, consequently, demonstrating the structure that creates the dehumanization process. We clarify that, considering the foundations of dehumanization, fighting against it must go beyond the subjective relational sphere, moving towards achieving the collective dimension of the class struggle against the capital. This process consists of articulating the particular struggle against the dehumanizing effects of the capital in health, with the general struggle against the capital in its most fundamental aspects .

Keywords: Capitalism; Health Care; Humanization; Marxism.
Neste ensaio, propomos uma análise da atual proposta de humanização do cuidado em saúde, enfatizando sua materialização na realidade brasileira, apreendida a partir de alguns enfoques trazidos na literatura científica com a qual dialogamos neste texto. Trata-se de um estudo teórico-conceitual, tendo por base o universo categorial marxiano. Portanto, procuramos contribuir, ainda que de modo preliminar, para a (re)formulação de uma linha teórica de análise da humanização do cuidado, obviamente, sem negar a produção já existente sobre o tema, ainda que esta não seja incorporada acriticamente.

Convém esclarecer que, atualmente, é possível constatar múltiplas definições para o termo "humanização", assim como formas diferentes de aplicá-lo no campo da saúde. Isso se deve ao fato do termo ser utilizado para designar um processo consubstanciado a partir de pontos de vista diversos (da política, da ética, da justiça etc.), acarretando o confronto de concepções distintas, expressas na polissemia e/ou no esvaziamento de sentido do referido termo (Souza; Moreira, 2008).

No âmbito da atenção à saúde, o termo "humanização" é utilizado no contexto do processo de cuidar. Para Mongiovi et al. (2014, p. 307), “a humanização da saúde é vista no contexto atual como um movimento integrador das relações da saúde, buscando uma melhoria do atendimento e um ambiente propício para o desenvolvimento do cuidado". Chama-se atenção à preservação da condição humana de quem é cuidado, mas também à reafirmação dos direitos e deveres dos atores envolvidos na qualidade da assistência em saúde, buscando-se garantir a integridade das relações profissional-usuário, com vistas a mudança nos modos de pensar e agir humanos (Cotta et al., 2013).

O conceito de humanização, embora atualmente possa abranger vários sentidos, teve sua origem no humanismo, transitando por, pelo menos, três sentidos: o primeiro como movimento intelectual, cujas bases se encontram nos séculos XIII e XIV, no Renascimento cultural europeu. 0 segundo sentido ligado aos princípios doutrinais acerca dos valores humanos, como solidariedade no humanismo cristão. E o terceiro, caracterizado pela ética nos costumes e 
convivência social com o outro. Todos esses sentidos, em alguma medida, estão relacionados à concepção de humanização na atualidade (Souza; Moreira, 2008).

Outro fator a ser considerado quando falamos de humanização (ou do seu inverso, a desumanização - processo de destituição da condição humana) é o surgimento do racionalismo cartesiano no século XVII, cujo raciocínio lógico e a necessidade advinda dele contribuíram para o domínio da razão científica moderna em saúde, manifestando-se, principalmente, no cuidado fragmentado, orientado por procedimentos ante a separação entre corpo e mente, objetividade e subjetividade. Com esse paradigma, desconsidera-se a experiência humana, bem como a determinação social do processo saúde-doença, acarretando um contexto no qual a doença sobrepuja o indivíduo humano, caracterizando a desumanização (Merhy; Franco, 2003; Souza; Moreira, 2008).

Embora tais práticas estejam mais explícitas na compreensão da relação usuário-profissional, devemos entender que esses fatores desumanizadores permeiam tanto as relações macro (sistema público de saúde) quanto as relações micro (usuário-profissionais).

Diante disso, na primeira seção, procuramos ilustrar as linhas fundamentais da atual discussão do nosso objeto de estudo, a fim de apreender alguns elementos para análise posterior. Na segunda seção, foi dada a ênfase para a Política Nacional de Humanização da Atenção e Gestão no Sistema Único de Saúde (PNH) e, na terceira, teceu-se crítica à proposta de humanização do cuidado em saúde, a partir do recorte da literatura aqui analisado e sob o prisma do materialismo histórico.

Para tanto, buscamos artigos na Biblioteca Virtual de Saúde (BVS) com a combinação dos seguintes descritores: "humanização do cuidado"; "humanização"; "cuidado"; "Sistema Único de Saúde”. Obteve-se o retorno de 209 textos, os quais foram submetidos aos seguintes critérios de inclusão: artigos publicados entre os anos 2004 e 2014 e que realizassem investigação sobre a realidade brasileira, obtendo-se 44 artigos. Além disso, utilizou-se como critério de exclusão: artigos repetidos e nos quais a humanização do cuidado era apenas assunto subjacente (isto é, não era foco de análise e, portanto, era citado de forma sumária nas discussões). Foram selecionados, ao final desse processo, 12 artigos.

Convém destacar que se constatou a predominância de abordagem sobre três enfoques temáticos: debate sobre o conceito de humanização (n=3), Política Nacional de Humanização da Atenção e Gestão no Sistema Único de Saúde - PNH (n=3) e sobre o cuidado específico no campo da enfermagem (n=3). Ademais, entre os 12 artigos, 6 foram publicados em periódicos da área de enfermagem e os outros 6, da saúde coletiva, o que explica a prevalência dos enfoques predominantes.

Por se tratar de um ensaio teórico-conceitual, o objetivo central não foi revisar os artigos selecionados, mas utilizá-los como suporte para a construção teórica pretendida. Também por conta disso, houve liberdade de incorporar outras fontes no processo, a exemplo dos materiais bibliográficos do acervo pessoal que abordassem os temas humanização e cuidado, além de documentos relacionados à PNH. As referências marxistas (em especial, Marx e Lukács), constituíram o lastro teórico da crítica desenvolvida.

\section{Humanização/desumanização e cuidado em saúde: algumas considerações conceituais presentes na produção teórica brasileira}

Inicialmente, cabe destacar que Corbani, Brêtas e Matheus (2009, p. 350) afirmam que "como humanos o que realizamos é humano, sendo, portanto, próprio ao ser humano visar o bem-estar da humanidade, tanto individual como coletivamente, isso é o verdadeiro sentido de humanizar", sendo a humanidade, "o espírito do homem, a essência humana, dotada de dignidade". Quando ocorre a nulidade dessa essência, surge o termo "humanização" "para encarar [significar] o processo de desumanização. Portanto, 'humanização' ou 'cuidado humanizado' mais sugerem um meio de suavizar as consequências do sistema do que o cuidado propriamente dito".

Ainda, segundo essas autoras, a humanização implicaria o envolvimento dos indivíduos, e o inverso disso indicaria um processo de desumanização, o 
qual ocorre a partir da prevalência do "ter" (riqueza) sobre o "ser" (conhecimento, natureza humana em essência). Esse "ter" ofuscaria os sujeitos, ao ponto de eles não enxergarem a própria condição humana, em sua plenitude. Corroborando, Souza e Moreira (2008) afirmam que a necessidade de humanização nos remete a algo perdido ou esquecido e que, portanto, merece ser resgatado: a dimensão pessoal.

Já para Casate e Corrêa (2012, p. 220-221) a humanização se refere aos aspectos de perceber o ser humano como um ser único e complexo, "o que inclui o respeito, o acolhimento, a empatia, a escuta, o diálogo, circunstâncias sociais, éticas, educacionais e psíquicas, além da valorização dos significados atribuídos pelo ser humano à sua experiência de adoecimento e sofrimento, da prevalência da comunicação e do diálogo". Quanto a isso, Deslandes (2004, p. 8), na análise que fez sobre a perspectiva do Ministério da Saúde, a partir dos documentos sobre a humanização da assistência, afirma que:

Geralmente emprega-se a noção de "humanização" para a forma de assistência que valorize a qualidade do cuidado do ponto de vista técnico, associada ao reconhecimento dos direitos do paciente, de sua subjetividade e referências culturais. Implica ainda a valorização do profissional e do diálogo intra e interequipes.

Em perspectiva similar à do Ministério da Saúde, Silva, Chernicharo e Ferreira (2011) afirmam que o conceito de humanização se agrega ao próprio conceito de cuidado, já que "cuidar não é somente um procedimento técnico [...] mas é principalmente usar da minha humanidade para assistir o outro - como ser único, em sua dignidade". Assim, estabelece-se a necessidade de humanizar o cuidado no sentido de incorporar dimensões humanas (psicológicas, sociais, políticas, espirituais, éticas) das subjetividades envolvidas no cotidiano do processo de cuidado.

Por sua vez, Ayres (2004, p. 28) possui uma abordagem que extrapola o âmbito do intercâmbio individual, pensando o processo coletivamente. 0 autor afirma que o conceito de humanizar, para além das suas implicações nas políticas de saúde, na gestão dos serviços, na formação e supervisão técnica e ética dos profissionais, significa, também, "transformar ações assistenciais propriamente ditas". Para isso, segundo o autor, deve-se unir o saber "não técnico com saber-técnico”. Por isso que, para ele, “a humanização passa pela radicalidade democrática do Bem comum. Não se Cuida efetivamente de indivíduos sem Cuidar de populações, e não há verdadeira saúde pública que não passe por um atento Cuidado de cada um de seus sujeitos".

Vejamos que, embora haja um amplo campo de significados no movimento de humanização na saúde, o recorte da literatura aqui analisado aponta para a desvalorização do aspecto pessoal-emocional nas relações que os indivíduos estabelecem entre si, uma vez que a realidade tem revelado "uma naturalização do não reconhecimento do outro como um igual" (o que demarcaria a denominada desumanização do cuidado) (Souza; Moreira, 2008, p. 328). Sobre isso, Corbani, Brêtas e Matheus (2009, p. 354) colocam que, "como a humanização é a prática do humano, falar em praticar o humano é evidenciar que o momento em que vivemos é de profunda desumanização, a ponto de ter de tomar o substantivo 'humanização' como verbo". Logo, nessa perspectiva, o momento que hoje é vivenciado na saúde necessita de profundas reflexões e mudanças que só acontecerão quando o saber profissional (a subjetividade de quem cuida) e o saber (subjetividade) de quem vivencia o processo saúde-doença unirem-se em favor do bem comum, a restauração da integridade do ser.

Conforme apontam Cotta et al. (2013), em se tratando de materialização dessa perspectiva, em face da realidade brasileira, o ponto culminante consiste na elaboração de uma política social pública específica para a humanização das práticas de saúde, trazendo, em especial, diretrizes para a atuação dos profissionais, conforme abordamos a seguir.

\section{A proposta de humanização da saúde como política social pública}

A Política Nacional de Humanização da Atenção e Gestão no Sistema Único de Saúde, conhecida apenas por $\mathrm{PNH}$, foi concebida em 2003, em meio aos avanços e contradições que permeavam o processo de institucionalização da proposta formulada nas lutas pela Reforma Sanitária (Pasche, 2009). 
Assim, a necessidade de humanizar como política surge em meio a um cenário em que, após avaliado o sistema público de saúde, foi constatado o despreparo dos profissionais para lidar com a dimensão subjetiva da produção do cuidado, considerando a presença de modelos de gestão centralizados e verticalizados que desapropriavam os trabalhadores de seu próprio processo de trabalho (Brasil, 2004). Dessa maneira, buscando enfrentar os desafios em melhorar a qualidade do atendimento público à saúde e valorizar o trabalho dos profissionais, surge a PNH, com três objetivos principais:

(1) enfrentar desafios enunciados pela sociedade brasileira quanto à qualidade e à dignidade no cuidado em saúde; (2) redesenhar e articular iniciativas de humanização do SUS e (3) enfrentar problemas no campo da organização e da gestão do trabalho em saúde que têm produzido reflexos desfavoráveis tanto na produção de saúde como na vida dos trabalhadores. (Pasche; Passos; Hennington, 2011, p. 4542)

Assim, humanizar, segundo a PNH, configura-se como a valorização dos diferentes sujeitos: usuários, trabalhadores e gestores, no processo de produção do cuidado. Tem como diretrizes: o acolhimento, a ampliação da clínica ampliada, a gestão democrática, a valorização do trabalhador traduzida em ações nas diversas práticas de saúde e esferas do sistema (Brasil, 2004).

$\mathrm{Na}$ análise documental que Deslandes (2004, p. 11) fez do discurso da humanização da assistência hospitalar, centrada no Programa Nacional de Humanização da Assistência Hospitalar (PNHAH), precursor da PNH, constatou-se que a perspectiva do resgate das subjetividades envolvidas no cuidado, mediante a valorização da dimensão subjetiva-individual (sobretudo, pessoalemocional, comunicacional e relacional), norteia o direcionamento teórico-metodológico da concepção de humanização adotada oficialmente:

humanizar é garantir à palavra a sua dignidade ética, em outros termos, o sofrimento, a dor e prazer expressos pelos sujeitos em palavras necessitam ser reconhecidas pelo outro (MS, 200oa), dado que as coisas do mundo só se tornam humanas quando passam pelo diálogo com os semelhantes.

Além disso, cabe salientar que essa proposta de valorização do âmbito subjetivo-individual considera a existência de um processo de precarização profissional em curso, mesmo que sem problematizar suas determinações mais profundas. Destaca que não se tem empreendido esforços adequados no sentido de melhorar "[a]s condições estruturais de trabalho [do] profissional de saúde, quase sempre mal remunerado, muitas das vezes pouco incentivado e sujeito a uma carga considerável de trabalho. Humanizar a assistência é humanizar a produção dessa assistência” (Deslandes, 2004, p. 13).

Tais questões, além de permanecerem como entraves à concretude do cuidado, contribuem para um processo de trabalho mecanizado. A fim de superar esse risco, a PNH ressalta o papel reflexivo dos trabalhadores e seu potencial criador a fim de transformar o que, a princípio, seria adverso, em um instrumento a seu favor (Brasil, 2004). Para tanto, ela ressalta a educação permanente dos trabalhadores e o processo de formação dos profissionais na graduação, pois tal processo ainda se encontra, segundo Souza e Moreira (2008), centrado no aprendizado técnico e individualizado, o que resulta, consoante Mongiovi et al. (2014) destacam, em profissionais despreparados para efetivar uma assistência humanizada.

Quanto a isso, é destacado o importante papel que as universidades exercem nessa formação, por constituírem um dos níveis de ensino que integra, ou deveria integrar, ensino e comunidade. Com efeito, ressalta-se que as universidades também possuem responsabilidade pelo processo de humanização, uma vez que o ensino-aprendizagem das práticas de saúde deve ser orientado pelas diretrizes da PNH. Entende-se, assim, a humanização como referencial na constituição de currículos, práticas e atitudes que formem profissionais que busquem, conscientemente, a integralização do cuidado (Souza et al., 2008; Casate; Corrêa, 2012; Chernicharo; Freitas; Ferreira, 2013; Nora; Junges, 2013; Cotta et al., 2013).

De acordo com Pasche, Passos e Hennington (2011), a PNH se concretiza, antes de tudo, como uma 
proposta metodológica, um modo de se fazer pela interação dos trabalhadores, gestores e usuários. Assim, para eles:

Valorizar os sujeitos é incluí-los nos diagnósticos institucionais e na construção de estratégias de superação dos problemas. Incluir o trabalhador é retirá-lo do lugar e posição que a gestão tradicional o colocou: como incapaz, a ponto de ter que ser gerido, e como indolente e perigoso, a ponto de ser controlado. Cuidar do cuidador não se faz tampouco por medidas piedosas e paternalistas. Cuidar é produzir com o outro possibilidades de alteração dos processos que originam sofrimento/ problemas de saúde, então "sinais e sintomas" de condições e modos de gestão e de organização do trabalho. (Pasche; Passos; Hennington, 2011, p. 4546)

Vejamos que os problemas que inauguram a PNH não são novos no Sistema Único de Saúde (SUS), alguns permanecem desde sua criação. Assim, a PNH como proposta metodológica, de acordo com Pasche (2009), busca concretizar um "SUS que dá certo”, pois embora a política tenha surgido a partir dos problemas evidenciados pelos usuários e trabalhadores, bem como pelos desafios que o SUS ainda enfrenta, não parte deles, mas sim das experiências e das ações dos sujeitos de forma coletiva, orientadas por princípios ético-políticos para produzir possibilidades de mudanças e concretização do "SUS que dá certo".

Assim, como política, a humanização na saúde orienta práticas assistenciais e de formação, que clamam o envolvimento de todos os sujeitos (gestores, trabalhadores e usuários) no processo do cuidar no SUS, centrando suas ações na postura subjetiva que esses atores assumem. Ainda que seja importante considerar essa faceta do combate à desumanização da saúde, constitui-se um hiperdimensionamento dela, implicando uma suposta busca da humanização sem serem consideradas as devidas conexões com a base objetiva imbricada no processo. Na sequência, ainda que de forma preliminar, apontamos as limitações dessa perspectiva, contrapondo-a a uma concepção de "humanização" fundamentada na teoria de Marx.

\section{Construindo uma crítica à proposta de humanização do cuidado em saúde}

Antes de qualquer coisa, é preciso resgatar o que dizem autores como Merhy e Franco (2003), ao apontarem uma importante dimensão na dinâmica do que vem sendo chamado de desumanização da saúde, quando destacam o caráter mercantil que norteia as práticas estabelecidas na sociedade moderna. Nessa direção, o cuidado em saúde se volta aos mecanismos de reprodução do capital, implicando uma racionalidade reificada sobre os diversos elementos da produção do cuidado, com sérias consequências para a subjetividade envolvida no processo.

Essa ideia, a nosso ver, é central para o desvelamento das raízes materiais da desumanização do cuidado, em sua determinação reflexiva (e recíproca) para com a dimensão subjetiva, possibilitando um horizonte de enfrentamento que considere a totalidade desse processo social. Ao mesmo tempo, ela nos remete à necessidade de aprofundar o caminho teórico-metodológico que permitiu sua delimitação inicial, recuperando premissas fundamentais a respeito da sociabilidade geradora da desumanização. É nesse ponto específico que se faz peremptório o retorno à teoria de Marx.

Nesse prisma analítico, constata-se que o cuidado, na sociedade capitalista, está subordinado ao valor - dimensão abstrata e quantitativa dos produtos da práxis humana, que expressa a subsunção das necessidades efetivamente humanas às necessidades do mercado, ou do valor de uso ao valor de troca (Marx, 1988) -, até mesmo porque a ciência, a tecnologia e os serviços (incluindo os de saúde), após a Revolução Industrial, tornaram-se mediações para a valorização do capital, com a produção crescente de equipamentos sofisticados e produtos farmacêuticos que movimentaram complexos industriais.

Merhy e Franco (2003) destacam essa questão ao apontarem a subsunção da produção do cuidado às "tecnologias duras" - os instrumentos, insumos, aparelhos em geral, fruto do avanço técnico-científico da modernidade e que, portanto, são resultados de trabalho anterior ("trabalho morto"). Esse processo de subsunção é necessário à reprodução do capital, no sentido de "realizar" a mais-valia cristalizada 
no "trabalho morto", implicando a reificação do "trabalho vivo em ato", configurado, ele mesmo, enquanto espaço para a produção de mais mais-valia. Por conta disso, os autores revelam o deslocamento crescente da subjetividade humana a um plano de passividade e subordinação, enfatizando a necessidade de recuperá-la, enquanto dimensão que define a condição humana do cuidado.

Com efeito, Merhy e Franco (2003) acabam conduzindo sua argumentação a uma estratégia de ação similar à que permeia a produção científica sobre a humanização da saúde, aqui já discutida, inclusive na PNH, uma vez que advogam a necessidade de desenvolver as "tecnologias leves" - aquelas que se definem na perspectiva relacional-subjetiva dos envolvidos na produção do cuidado - como eixo decisivo para a recuperação da condição humana do cuidado. Mas percebamos que os autores ampliam o horizonte, problematizam a dinâmica objetiva do processo de valorização presente na base da desumanização, alçando-nos a possibilidades que vão além da perspectiva relacional. Mesmo sem aprofundar a discussão sobre essas possibilidades, o “diagnóstico" feito pelos autores nos dão elementos importantes para se pensar outros caminhos que nos levem ao enfrentamento dessa problemática, na sua raiz.

Nessa perspectiva, vale destacar que o cuidado, assim como qualquer práxis, é atividade humana sensível, na qual se consubstancia idealização e ação, subjetivação e objetivação. Portanto, considerando a apreensão do caráter ontológico do trabalho (e da práxis em geral) feita por Marx (1988) e, posteriormente, corroborada por Lukács (2013), o cuidado, enquanto práxis particular, é um "entrelaçamento" de teleologia e causalidade. Ou seja, tal qual o modelo originário do trabalho (enquanto intercâmbio orgânico entre homem e natureza), quem cuida projeta essa ação idealmente antes de objetivá-la; trata-se, pois, de ação teleologicamente direcionada. Contudo, a exteriorização desse plano ideal ocorre como identidade da não identidade, pois se depara com uma série de cadeias causais (causalidade), que fogem ao controle direto do seu executor. No caso do cuidado, a causalidade engloba desde aspectos biológicos (inerentes a quem recebe o cuidado) até os sociais, como as condições de prestação do cuidado, o nível de desenvolvimento do saber próprio daquela práxis, as relações de interdependência com outros profissionais no interior da divisão técnico-científica da saúde, as relações sociais às quais está imerso o indivíduo ou a coletividade que receberá o cuidado etc.

Destarte, o cuidado é inerente ao ser humano, existe desde o surgimento da vida humana, com a finalidade de permitir a sobrevivência dos indivíduos, ajudar o outro a viver afastando aquelas ameaças à saúde (Oguisso, 2007). Ou seja, possui função social objetiva, na medida em que, em sua essência, sustenta-se no ato do ser humano ajudar outro(os) indivíduo(s) no atendimento das suas necessidades humanas essenciais, como comer, vestir, abrigar-se, repousar, entre outras, a fim de conservar-lhe a vitalidade, a saúde - o que Silva e Cavalcanti (2013) denominam de cuidado em geral.

Enquanto práxis, o cuidado é inseparável do âmbito do ser social, o que comprova seu caráter humano, mesmo nas formas mais instintivas. Assim como no caso do trabalho, o cuidado se complexifica, gerando novas formas e possibilidades de praticá-lo, tornando-se humanizado, na medida em que, sem suprimir o seu caráter natural (instintivo), eleva-se para um novo nível, o social. Portanto, o cuidado é essencialmente atividade humana, mas que, sob certas determinações sociais, implica reificação (desumanização) dos sujeitos partícipes do processo, o que vem suscitando estratégias de humanização, tais quais a PNH.

Dessa forma, a proposta de humanização carrega em si uma ambiguidade, uma vez que se busca humanizar algo que já é humano, aspecto já apontado, preliminarmente, por Corbani, Brêtas e Matheus (2009). Contudo, essa ambiguidade não é mera questão epistemológica, mas reflexo do caráter contraditório da forma de sociabilidade que converte o cuidado em um processo desumano. Nesse sentido, a pergunta à qual, antes de qualquer coisa, deve-se procurar responder é: quais as determinações do processo de desumanização em geral (e, consequentemente, do processo de cuidar)?

Marx (1988), ao discutir o trabalho em termos ontológicos, demonstra como se dá o processo de humanização. Lembremos que o trabalho é o intercâmbio entre o homem e a natureza, processo 
pelo qual o homem, ao mesmo tempo que transforma matéria natural para atender suas necessidades, se transforma, se complexifica e se autoconstrói enquanto ser social. Desse processo, engendra-se a humanização, o tornar-se homem, submissão das forças naturais (seus instintos naturais) à ação humana projetada, culminando com o surgimento de um novo ser, o ser social.

O conceito marxiano de humanização, portanto, refere-se à capacidade de o homem se autoproduzir na transformação da natureza, modificando-se conscientemente, apropriando-se daquilo que gerou, assim como permitindo a consubstanciação de novas práticas humanas, novas práxis (como o cuidado).

Através da análise do trabalho em geral (em suas determinações ontológicas mais genéricas), Marx (1988) apresenta as bases para a humanização. Já pela análise da forma de trabalho peculiar no capitalismo, ele revela as raízes do processo de desumanização. Isso porque o processo de trabalho, sob a égide do capital, é processo de valorização: produção de valor. Ou seja, não é direcionado ao livre atendimento das necessidades humanas, mas, ao invés disso, volta-se para o atendimento das necessidades do mercado, o que pressupõe extração de mais-valia de quem produz diretamente o valor.

Vale fazer a ressalva de que a característica mais geral do trabalho, de ser produtor de valor de uso, permanece válida no capitalismo, sendo que subordinada ao processo de valorização, sobressaindo o valor de troca. Tal condição confere o caráter dual ao trabalho no capitalismo, tão explorado por Marx (1988) no capítulo V de $O$ Capital. Em termos ontológicos, como diria Lukács (2013), podemos afirmar que o trabalho, no sistema do capital, conserva sua universalidade, mas se particulariza sob a forma de processo de valorização.

Nessas condições, a mercadoria, criatura da mão humana, passa a dominar seu criador, em um processo alienante ao qual Marx (1988) chamou de fetichismo da mercadoria. Os homens passam a se reconhecer, sobretudo, como compradores e vendedores (o que pressupõe a expropriação dos meios de produção em relação aos trabalhadores); isto é, as relações mercantis passam a ser o eixo regente da vida social. Como alerta Marx (1988), as mercadorias não vão sozinhas ao mercado, mas "forçam" (como uma força abstrata de dominação) os homens a efetivarem sua realização, sob a pena de não terem suas necessidades atendidas, ainda que sejam necessidades forjadas sob a ideologia do capital. Para Gorender (1996, p. 34, grifo no original),

Por conseguinte, a teoria marxiana conduz à desmistificação do fetichismo da mercadoria e do capital. Desvenda-se o caráter alienado de um mundo em que as coisas se movem como pessoas $e$ as pessoas são dominadas pelas coisas que elas próprias criam. Durante o processo de produção, a mercadoria ainda é matéria que o produtor domina e transforma em objeto útil. Uma vez posta à venda no processo de circulação, a situação se inverte: $o$ objeto domina o produtor.

Voltado à produção de valor, o trabalho é contravertido; isto é, ainda que permaneça sendo o responsável pelo "tornar-se humano", na sua forma abstrata ele corresponde à base da reificação e degradação humana. Portanto, o caráter desumano tanto comparece no fato de reificar os sujeitos partícipes do processo de cuidar (e, por conseguinte, contraverter o próprio cuidado, tornando-o mercadoria) quanto no fato de determinar um processo de degradação da saúde humana, expresso em diversas situações que demandam formas de cuidado que a sociedade capitalista não pode oferecer. Engendra-se uma espiral na qual a relação saúde e desumanização se constitui a partir de diversas dimensões, que convergem no sentido de reproduzir o capital (e seu caráter desumano) e impedir o pleno desenvolvimento humano, inclusive (para o caso aqui em questão) no que concerne à prática do cuidado, visto que reifica cuidadores, indivíduos que necessitam do cuidado e as relações que se estabelecem entre eles.

Diante disso, constatamos que a desumanização é um processo geral que ocorre sob o capitalismo, no qual o ser humano é reduzido à "coisa”; suas ações, ao processo de valorização; e suas necessidades relegadas ao mercado. É importante esclarecer que, na esteira de Marx (1988) e Lukács (2013), as atividades humanas nas quais o tipo de intercâmbio desenvolvido pressupõe, nos dois polos, seres humanos; não se tem trabalho em termos universais, 
ontológicos (aquele no qual, em um polo, há ser humano e, no outro, natureza não humana). É o caso do cuidado, das práticas de saúde, de todas as demais práxis particulares que operam com esse tipo de intercâmbio. Obviamente, essa condição universal se particulariza de diferentes formas ao longo da história. Hoje, na sociedade capitalista, a expansiva mercantilização das atividades humanas impele que todas essas atividades "vistam a roupagem" de trabalho assalariado, de atividade realizada por intermédio do mercado. Só nesse sentido particular que falamos do cuidado em saúde como trabalho, mas não sendo aquele que, universalmente, funda o ser social.

Uma vez que o trabalho é a categoria fundante de todas as práxis particulares, e o cuidado como práxis guarda semelhança com o trabalho (entendido no seu sentido mais universal, ontológico, enquanto intercâmbio entre homem e natureza), tem-se a reprodução dessa lógica desumanizadora para o âmbito do cuidado em saúde. Embora o cuidado, por ser inerente ao ser humano, mantenha sua essência como atividade na qual o ser humano ajuda o outro a viver, essa essência, na lógica mercantil, passa a ser subordinada ao processo de valorização, imprimindo assim, as marcas desumanas do capital na prática do cuidado em saúde (Souza, 2016).

Assim, a desumanização é um processo com importante dimensão objetiva e não pode ser visto apenas do ponto de vista de adequação aos preceitos divinos ou na sua dimensão subjetiva, comunicacional ou relacional. Essa concepção limitada à dimensão subjetiva, como vimos, comparece em Casate e Corrêa (2012, p. 220-221), ao dizerem que a locução "humanização" refere-se aos aspectos de perceber o ser humano como um ser único e complexo, "o que inclui o respeito, o acolhimento, a empatia, a escuta, o diálogo, circunstâncias sociais, éticas, educacionais e psíquicas, além da valorização dos significados atribuídos pelo ser humano à sua experiência de adoecimento e sofrimento, da prevalência da comunicação e do diálogo". Isso se reproduz na PNH e em parte da produção científica que apresentamos, a partir dos quais se identifica uma proposta na qual a desumanização do cuidado seria revertida tendo como eixo principal a transformação da relação profissional-usuário, com suas mútuas percepções, incluindo e aperfeiçoando as estratégias de acolhimento, comunicação, diálogo e interação.

Considerar somente esses aspectos subjetivos, no processo humanização-desumanização no cuidado, é abstrair os indivíduos da realidade social que estão inseridos e do processo histórico-social que está por trás disso: o processo de valorização e o antagonismo de classe que lhe é corolário. 0 capital, para continuar se reproduzindo, cria/ impulsiona desigualdades, transforma desde a natureza até os cuidados em mercadoria, ao passo que aliena o trabalhador de sua condição humana. Portanto, não se trata, apenas, de percepção individual, valorização subjetiva ou envolvimento emocional e comunicacional, ainda que tudo isso tenha importância. Falar em humanização em uma sociedade que produz condições desumanizadoras, sem vislumbrar um horizonte de enfrentamento de suas raízes materiais, é deparar-se com ações de alcance limitado.

Por isso mesmo, a análise de Merhy e Franco (2003) possui mérito ao revelar elementos presentes no processo originário da desumanização da saúde, a partir da crítica ao modo de produção capitalista, bem como por defender o resgate da mediação ativa da práxis humana do cuidado, sobretudo na sua dimensão relacional. Feito isso, é preciso, agora, avançar no sentido de demonstrar que o enfrentamento da desumanização pautado, apenas, nessa dimensão, embora importante, é limitado, porquanto não se trata de um problema meramente da seara subjetiva dos indivíduos, mas de um processo com raízes objetivas, construídas histórico-socialmente e que, portanto, demanda um outro tipo de enfrentamento.

Por esse caminho, sem ignorar a relevância de estabelecer estratégias que fortaleçam a dimensão relacional do cuidado, destacamos, sobretudo, os limites existentes em assumir essa estratégia sem uma perspectiva de enfrentamento da desumanização pela raiz. Por conseguinte, afirmamos a necessidade - prioritária - de extrapolar a dimensão interna do cuidado individualizado, lançando-se em direção à dimensão coletiva da luta de classes, de enfrentamento direto com o capital e suas contradições particulares, combatendo o mal pela raiz. 
Destacamos, desta feita, a importante posição das lutas pela saúde, como dimensão particular das lutas de classe. Consoante apontam Souza, Melo e Vasconcellos (2015), a classe trabalhadora - o sujeito diretamente envolvido e atingido pela dinâmica do capital - possui o protagonismo no processo universal de luta contra o capitalismo, mas deve fazer isso sem diluir as diversas formas particulares de expressão do caráter destrutivo desse modo de produção. Uma dessas formas, decerto, é a degradação da saúde conjugada a reificação das práticas de cuidado: lutar contra essa particularidade, mas de forma articulada à luta mais geral, é conditio sine qua non para o sucesso do combate à desumanização em geral e, em particular, na saúde.

\section{Considerações finais}

Constamos alguns enfoques temáticos na literatura que investigamos: conceituação da humanização em saúde, PNH e cuidado de enfermagem. Estabelecemos diálogo com esses enfoques, em suas diferentes abordagens a depender do autor. Sobressaiu-se a discussão sobre a PNH, com os princípios e diretrizes que institui. Esses, inclusive, passam a balizar parte da produção teórica a respeito da temática em questão, quando foi possível constatar uma ênfase à dimensão subjetivarelacional no ato de cuidar.

Essa dimensão se faz importante por amenizar alguns efeitos do processo de desumanização (aliviar sofrimento, estabelecer comunicação e interação mais empáticas entre sujeito-usuário etc.). Todavia, em uma perspectiva crítica, problematizamos a necessidade de ultrapassar essa dimensão e, por conseguinte, debruçar-se sobre as raízes desse processo. Aqui, apresentamos uma perspectiva que busca avançar no sentido do desvelamento das bases do processo de desumanização em geral (e, em específico, na saúde), tendo o universo categorial marxiano como referencial teórico-crítico.

Tecer as devidas correlações entre a reificação humana engendrada no processo de valorização (logo, de produção e reprodução do capital) e a reificação particular da saúde mostrou-se um ponto de partida profícuo para ampliar o debate sobre a humanização do cuidado em saúde. Para além das contribuições que a literatura sobre o assunto (aquela que coloca o eixo da humanização do cuidado em saúde nas relações subjetivas profissional-usuário) e a PNH nos oferece, precisamos pensar a desumanização da saúde no bojo da luta de classes, como expressão dos antagonismos basilares do capital, enfrentando-os no interior do âmbito particular da saúde, mas de forma articulada com a luta mais geral de superação do capital.

Precisamos reconstruir as estratégias revolucionárias, recuperar o horizonte de reformulação da sociedade pela sua base (sem ignorar os avanços pontuais que as estratégias do aqui e agora possam proporcionar). Acreditamos que só o enfrentamento radical do capital, visando reverter a subordinação das necessidades humanas às necessidades do mercado, pode emancipar a condição humana do processo do cuidado, hoje subsumida à valorização. Esse deve ser o primado daqueles que estudam e militam na saúde contra a desumanização do cuidado.

\section{Referências}

AYRES, J. R. C. M. O cuidado, os modos de ser (do) humano e as práticas de saúde. Saúde e Sociedade, São Paulo, v. 13, n. 3, p. 16-29, 2004.

BRASIL. HumanizaSUS: Documento base para gestores e trabalhadores do SUS. Brasília, DF: Ministério da Saúde, 2004.

CASATE, J. C.; CORRÊA, A. K. A humanização do cuidado na formação dos profissionais de saúde nos cursos de graduação. Revista da Escola de Enfermagem da USP, São Paulo, v. 46, n. 1, p. 219226, 2012.

CHERNICHARO, I. M.; FREITAS, F. D. S.; FERREIRA, M. A. Humanização do cuidado de enfermagem: contribuição ao debate sobre a Política Nacional de Humanização. Revista Brasileira de Enfermagem, Brasília, DF, v. 66, n. 4, p. 564-570, 2013.

CORBANI, N. M. S.; BRÊTAS, A. C. P.; MATHEUS, M. C. C. Humanização do cuidado de enfermagem: o que é isso? Revista Brasileira de Enfermagem, Brasília, DF, v. 62, n. 3, p. 349-354, 2009. 
COTTA, R. M. M. et al. Debates atuais em humanização e saúde: quem somos? Ciência \& Saúde Coletiva, Rio de Janeiro, v. 18, n. 1, p. 171-179, 2013.

DESLANDES, S. F. Análise do discurso oficial sobre a humanização da assistência hospitalar. Ciência \& Saúde Coletiva, Rio de Janeiro, v. 9, n. 1, p. 7-14, 2004.

GORENDER, J. Apresentação. In: MARX, Karl. $O$ Capital: crítica da economia política. 5. ed. São Paulo: Nova Cultural, 1996. Livro primeiro, tomo I, p. 5-70.

LUKÁCS, G. Para uma ontologia do ser social II. São Paulo: Boitempo, 2013.

MARX, Karl. O Capital: crítica da economia política. 3. ed. São Paulo: Nova Cultural, 1988. Livro primeiro, tomo I.

MERHY, E. E.; FRANCO, T. B. Por uma composição técnica do trabalho em saúde centrada no campo relacional e nas tecnologias leves: apontando mudanças para os modelos tecno-assistenciais. Saúde em Debate, Rio de Janeiro, v. 27, n. 65, p. 316-23, 2003.

MONGIOVI, V. G. et al. Reflexões conceituais sobre humanização da saúde: concepção de enfermeiros de unidades de terapia intensiva. Revista Brasileira de Enfermagem, Brasília, DF, v. 67, n. 2, p. 306-311, 2014.

NORA, C. R. D.; JUNGES, J. R. Política de

Humanização na Atenção Básica: revisão sistemática. Revista de Saúde Pública, São Paulo, v. 47, n. 6, p. 1186-1200, 2013.

OGUISSO, T. Trajetória histórica e legal da enfermagem. 2. ed. ampl. Barueri: Manole, 2007.

PASCHE, D. F. Política Nacional de Humanização como aposta da produção coletiva de mudanças nos modo de gerir e cuidar. Interface Comunicação, Educação, Saúde, Botucatu, v. 13, p. 701-708, 2009. Suplemento 1.

PASCHE, D. F.; PASSOS, E.; HENNINGTON, É. A. Cinco anos da Política Nacional de Humanização: trajetória de uma política pública. Ciência \& Saúde Coletiva, Rio de Janeiro, v. 16, n. 11, p. 45414548, 2011.
SILVA, F. D.; CHERNICHARO, I. M.; FERREIRA, M. A. Humanização e desumanização: a dialética expressa no discurso de docentes de enfermagem sobre o cuidado. Escola Anna Nery Revista de Enfermagem, Rio de Janeiro, v. 15, n. 2, p. 306-313, 2011.

SILVA, S. E. V.; CAVALCANTI, F. M. S. O processo de formação do enfermeiro brasileiro. Edufal: Maceió, 2013.

SOUZA, D. O. A saúde na perspectiva da 'ontologia do ser social'. Trabalho, Educação e Saúde, Rio de Janeiro, v. 14 n. 2, p. 337-354, 2016.

SOUZA, D. O.; MELO, A. I. C.; VASCONCELLOS, L. C. F. A saúde dos trabalhadores em "questão": anotações para uma abordagem históricoontológica. O social em questão, Rio de Janeiro, v. 18, n. 34, p. 107-136, 2015.

SOUZA, J. C. et al. Ensino do cuidado humanizado: evolução e tendências da produção científica. Revista Brasileira de Enfermagem, Brasília, DF, v. 61, n. 6, p. 878-882, 2008.

SOUZA, W. S.; MOREIRA, M. C. N. A temática da humanização na saúde: alguns apontamentos para debate. Interface Comunicação, Educação, Saúde, Botucatu, v. 12, n. 25, p. 327-338, 2008.

\section{Contribuição dos autores}

Diego de Oliveira Souza selecionou e analisou as referências utilizadas na pesquisa, participou da redação de todo o artigo e realizou a revisão final. Jane Carla Maurício concebeu a ideia inicial do artigo, selecionou e analisou as referências utilizadas e participou da redação da introdução, primeira e segunda seções do artigo.

Recebido: 02/06/2016

Reapresentado: 17/11/2017

Aprovado: 16/02/2018 